\title{
Stress and Dominance in a Social Fish
}

\author{
Helen E. Fox, ${ }^{1}$ Stephanie A. White, ${ }^{2}$ Mimi H. F. Kao, ${ }^{3}$ and Russell D. Fernald ${ }^{2}$ \\ ${ }^{1}$ Department of Integrative Biology, University of California at Berkeley, Berkeley, California 94720, and ${ }^{2}$ Neuroscience \\ Program and ${ }^{3}$ Program in Human Biology, Stanford University, Stanford, California 94305-2130
}

\begin{abstract}
Many aspects of reproductive physiology are subject to regulation by social interactions. These include changes in neural and physiological substrates of reproduction. How can social behavior produce such changes? In experiments reported here, we manipulated the social settings of teleost fish and measured the effect (1) on stress response as reflected in cortisol production, (2) on reproductive potential as measured in production of the signaling peptide, gonadotropin-releasing hormone, and (3) on reproductive function measured in gonad size. Our results reveal that the level of the stress hormone cortisol depends critically on both the social and reproductive status of an
\end{abstract}

individual fish and on the stability of its social situation. Moreover, the reproductive capacity of an individual fish depends on these same variables. These results show that social encounters within particular social contexts have a profound effect on the stress levels as well as on reproductive competence. Social behavior may lead to changes in reproductive state through integration of cortisol changes in time. Thus, information available from the stress pathway may provide socially relevant signals to produce neural change.

Key words: gonadotropin-releasing hormone; stress; dominance; cortisol; plasticity; reproduction; teleost; cichlid
How does behavior influence the brain? Although this question is explored less often than its converse, understanding the mechanisms through which behavioral encounters can modify neural structures may reveal general patterns of social influence on physiology. The reproductive axis is a primary locus for this influence, typically suppression of reproductive maturation or competence of an individual by the presence of dominant conspecifics (in mammals: Payman and Swanson, 1980; Faulkes et al., 1991; McKittrick et al., 1995; Bennett et al., 1996; Saltzman et al., 1996; in fish: Leitz, 1987; Cardwell and Liley, 1991; Pankhurst and Barnett, 1993; Cardwell et al., 1996). In our model system, the African cichlid fish Haplochromis burtoni, $\sim 25 \%$ of males defend territories and thereby dominate food resources and access to females. Moreover, these territorial males (Ts) suppress the reproductive maturation of the remaining subordinate nonterritorial males (NTs) (Fernald and Hirata, 1977a). Ts are behaviorally active, are bright blue or yellow, and display an eyebar. Their territories include the food resource: detritus accumulated in the shore pools of Lake Tanganyika (Fernald and Hirata, 1977b). In contrast, NTs are sandy gray, lack an eyebar, and mimic the schooling females to gain access to food. Within an NT's hypothalamo-preoptic area (POA), neurons that secrete the critical reproductive peptide gonadotropin-releasing hormone (GnRH) are eightfold smaller on average than those of Ts (Davis and Fernald, 1990; Francis et al., 1993). Consequently, NTs have unspermiated testes, which prevents reproduction (Fraley and Fernald, 1982).

Received Feb. 24, 1997; revised April 29, 1997; accepted May 30, 1997.

This work was supported by National Institutes of Health Grant NS 34950 to R.D.F. We thank T. Nguyen, R. Robison, and many members of the Fernald lab for assistance with tissue collection, P. Morales of the California Academy for instruction in necropsy, and J. Byun for measuring soma sizes. S. Bunge, K. Hoke, R.

Robison, R. Sapolsky, R. White, and two anonymous reviewers provided helpful comments about earlier versions of this manuscript.

H.E.F. and S.A.W. contributed equally to this work.

Correspondence should be addressed to Russell D. Fernald, Psychology Department, Building 420, Stanford University, Stanford, CA 94305-2130.

Copyright (C) 1997 Society for Neuroscience $0270-6474 / 97 / 176463-07 \$ 05.00 / 0$
The phenotypic plasticity of $H$. burtoni male status compensates for this apparent evolutionary disadvantage. In contrast, in the plainfin midshipman Porichthys notatus, the two developmental routes for males are both reproductive but are terminally differentiated, with body plan and behavioral characteristics maintained until death (for review see Bass, 1992); however, nonterritoriality among $H$. burtoni males is socially controlled. The brightly colored, active Ts are conspicuous prey for piscivorous birds (Fernald and Hirata, 1977a), an obvious loss of their reproductive advantage. Consequently, when territories become available, nearby NTs quickly move in, adopting territorial behaviors and coloration. More slowly, these animals transform physiologically to enable reproduction (Francis et al., 1993; Nguyen, 1996). Reproductive opportunity then outweighs predation risk associated with territorial flamboyance.

How do social cues produce this maturational plasticity? The default developmental pathway is reproductive maturation, because males raised alone become Ts (Fernald and Hirata, 1979). Juvenile $H$. burtoni males adopt the NT developmental route in response to visual and tactile cues from older conspecifics (for review, White and Fernald, 1997). The transduction of social behavior into reproductive consequence requires an endogenous mediator whose production fluidly tracks social events and whose signal, integrated over time, sculpts changes in gene expression. Several lines of evidence suggest that the glucocorticoid stress hormone cortisol might serve this function: increased secretion of cortisol is a primary indicator of stress in teleost fish (for review, see Wendelaar Bonga et al., 1995). Changing social settings can produce changes in cortisol levels in mammals (Manogue et al., 1975; Sapolsky, 1986, 1993; Alberts et al., 1992; Gust et al., 1993; Johnson et al., 1996), birds (Schwabl et al., 1988), and fish (cf. Pottinger, 1992; for review, see Billiard et al., 1981; Schreck, 1981). Stress suppresses the reproductive axis (mammals: Rivier and Rivest, 1991; Sapolsky, 1993; newts: Moore and Miller, 1984; fish: Leitz, 1987; Pickering et al., 1987). Finally, stress steroids can 

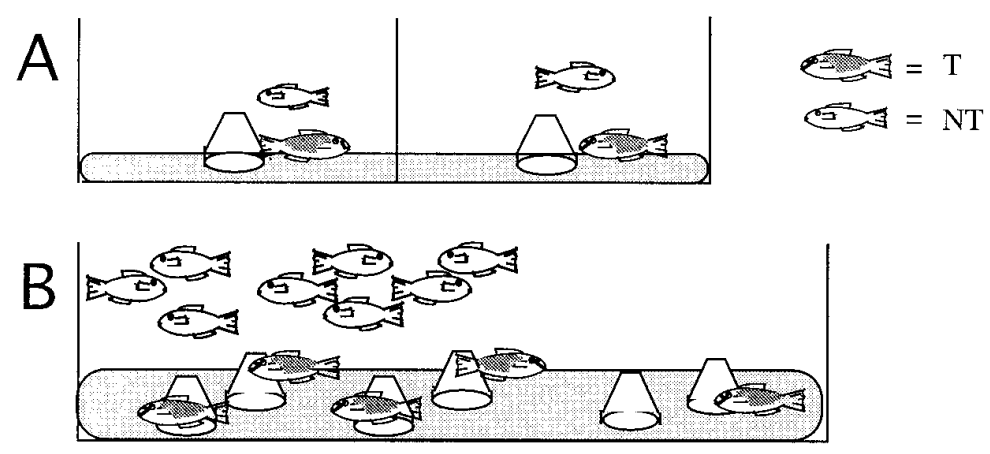

Figure 1. Schematic representation of three experimental groups, showing relative tank dimensions and densities of $\mathrm{T}$ and NT males. $A$, Social pairs; $B$, highdensity community tank; $C$, low-density community tank with under-gravel feeding via substrate tubing. The ratio of males to females (not shown) in each tank was 1:2 (community settings) or 1:3 (social pairs).

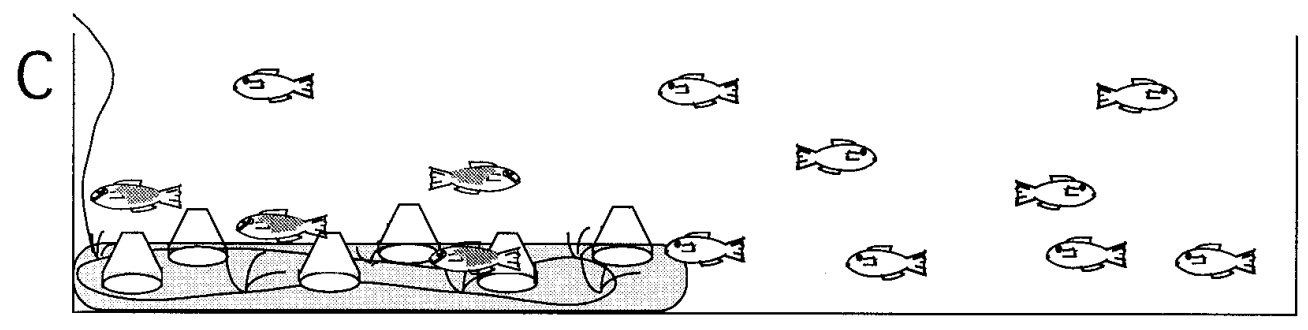

alter gene expression by binding to intracellular glucocorticoid receptors leading to dimerization, nuclear entry, and transcriptional activation or repression of genes bearing consensus elements in their upstream promoter regions (cf. Meisfeld et al., 1986).

To understand how social opportunity translates into physiological change in male $H$. burtoni, we manipulated the social setting and measured stress response with cortisol production and measured reproductive potential with the production of $\mathrm{GnRH}$ and gonad size. Our results show that cortisol levels depend on both individual dominance and reproductive status and on social stability, and that the reproductive opportunity of any individual hinges on temporal features of the social situation.

\section{MATERIALS AND METHODS}

\section{Maintenance}

Fish were bred and reared under laboratory conditions that mimic those of their natural environment (Fernald and Hirata, 1977a,b): $\mathrm{pH} 7.8-8.2$, $29^{\circ} \mathrm{C}$, and $12 \mathrm{hr}$ light/dark cycle with full-spectrum illumination. Gravel and terra-cotta pot shards were provided, which allow the dominant Ts to establish and maintain the territories necessary for successful reproductive behavior (Fernald, 1977). Unless otherwise noted, fish were fed daily at 9:00-9:30 A.M. with cichlid pellets and flakes (Aquadine).

\section{Experimental groups}

The effect of social setting on stress and reproductive capacity in male fish was determined by using different tank sizes and varying the number of males in each tank (Fig. 1). Throughout all groups, the ratio of males to females was between 1:2 and 1:3.

Social pairs. The first study was designed to reveal stress profiles and reproductive status in animals at the extremes of social status, a $\mathrm{T}$ and an NT. Only males that had maintained a stable social status for at least 2 months were used. Matched-age pairs consisted of either young fish $(<1$ year old) or older fish ( $>2$ year old). In each case, one T was paired with one NT, along with six females, in a "hemi-tank" [20 (height) $\times 50$ $($ depth $) \times 40$ (width) $\mathrm{cm}]$ : a full-sized tank bisected by a clear perforated Plexiglas divider. Fish in one hemi-tank could interact chemically and visually, but not physically, with those in the adjacent hemi-tank. This social setting was intended to maintain animals within their already established social states (Kao, 1993) by allowing Ts to attack NTs and females with impunity because no other $\mathrm{T}$ was present as an opponent. Visual interaction with the $\mathrm{T}$ male in the neighboring hemi-tank provided a stimulus for threat and border displays (see "Behavioral obser- vations" below). The single NT in each hemi-tank received the brunt of the T's aggressive behavior because there were no other NTs to attack.

Community tanks. The effect of social setting on stress and reproductive state was explored in more naturalistic social situations by introducing many males into larger tanks where they could establish social hierarchies rather than remain either T or NT relative to only one other male (as imposed by the hemi-tanks). Two high-density tanks [25 $($ height $) \times 45($ depth $) \times 90$ (width) cm, $100 \mathrm{l}]$ contained $12-14$ males and 24 females, and one low-density tank held the same number of males and females in a larger volume aquarium [35 (height) $\times 45$ (depth) $\times 152$ (width) cm, 240 l]. In the large, low-density tank, gravel and pot shards were placed only on one half of the tank so that the other half could provide a refuge for NTs. To imitate the feeding conditions of their natural environment, a slurry of crushed flakes and water was delivered with an infusion pump (Harvard Apparatus, S. Natick, MA) via surgical tubing buried in the graveled half of the tank over the course of 2-3 hr. Fish sifted for residual food in the gravel throughout the day.

\section{Behavioral observations}

Each male was observed for $3 \mathrm{~min}$, three times per week, starting between 11 A.M. and 1 P.M. Behaviors were identified using a standard guide (Fernald, 1977) and included aggression (chasing or biting females or NTs), aggression toward Ts (chasing or biting Ts, threat and border displays, and fighting), reproductive acts (digging, courting, and spawning), and submissive acts (fleeing). Each behavior was recorded, as was the overall coloration of the fish and the presence or absence of an eyebar. Males were classified as T, NT, or NT/T on the basis of their behavior and coloration. The NT/Ts were in a "transition" state and exhibited behaviors and color patterns typical to both types of males. The location of the territory of Ts and the school of females and NTs was also recorded.

We measured the stability of a community's social structure with an "index of stability" (S) to compare within and between tanks across sampling periods. The number of Ts (the source of the tank hierarchy) was divided by the number of times any fish changed status between blood sampling dates [T $\leftrightarrow$ NT counts as one switch; (T or NT) $\leftrightarrow \mathrm{NT} / \mathrm{T}$ counts as $1 / 2$ ]: $S=$ (no. Ts)/(no. status switches by all fish between blood sampling dates). A higher index of stability corresponds to a more stable tank, because the relative frequency of fish changing social state is decreasing.

\section{Blood sampling and radioimmunoassay $(R I A)$}

Blood was collected from all males to determine cortisol levels. In social pairs, blood samples were taken at 1 and 2 weeks after fish were placed in their hemi-tanks. In high-density community tanks, blood sampling began 2 months after establishment and took place monthly (four dates 


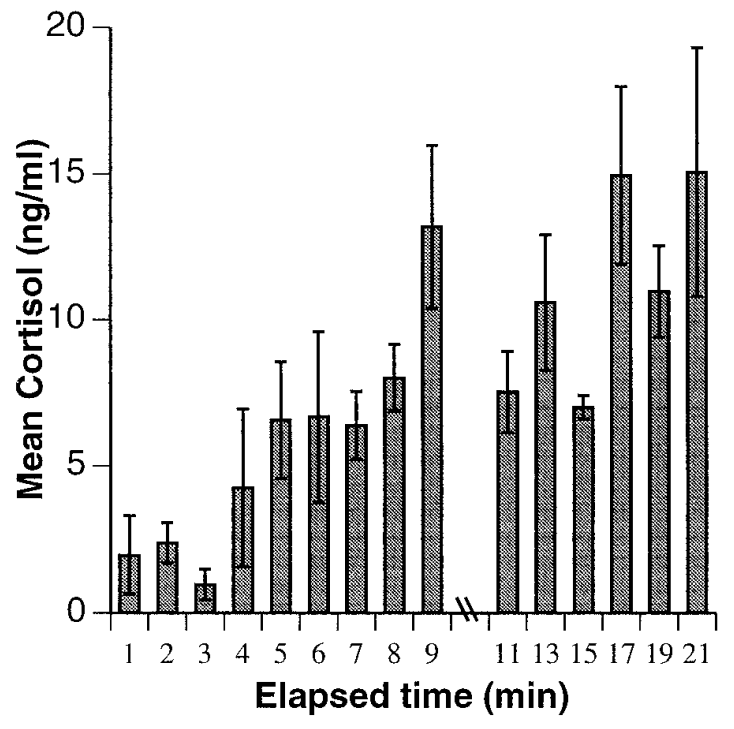

Figure 2. The stress response as measured by serum cortisol levels in Haplochromis burtoni as a function of time after onset of the stressor which was removal of aquarium lid. Until 4 min after stress onset, cortisol levels remain below basal levels of $5.0 \mathrm{ng} / \mathrm{ml}$. After this time, cortisol concentration rises substantially, suggesting that additional cortisol synthesized in response to the stress of capture. Accordingly, only blood collected within 4 min of aquarium lid removal was used for analysis. Differing cortisol levels in fish sampled within the first 4 min also highlight the divergent experiences of individuals during the previous $30 \mathrm{~min}$ of social interactions. Indeed, it is extremely difficult to obtain true basal levels of cortisol, because the fish are constantly interacting, and even social isolation has been shown to be stressful (Pottinger, 1992).

total). To observe the development of community stability in the lowdensity setting, blood sampling began 3 weeks after establishment and took place at 2 week intervals (three dates total). We have shown that in $H$. burtoni there is $\sim 4 \mathrm{~min}$ lag time between capture and serum cortisol increase (Fig. 2) (Kao, 1993). Because cortisol is not stored and must be synthesized from cholesterol in the adrenal gland before its release into the blood stream, circulating levels of cortisol reflect stresses that have occurred $>4$ min before sampling. With continued chasing, cortisol levels rise dramatically above basal levels, suggesting that high levels of cortisol are stress-induced, rather than attributable to day-to-day variation. To acquire blood samples that were not influenced by capture stress, animals were caught, and 20-100 $\mu \mathrm{l}$ of blood was drawn within 4 min after the removal of the aquarium lid. Samples were obtained from the caudal sinus, aligned below the end of the dorsal fin and just ventral to the lateral line, using a heparinized butterfly needle and catheter $(25 \times 3 / 4,12$ inch tubing; Abbott Laboratories, N. Chicago, IL). Blood was kept in heparinized $1.5 \mathrm{ml}$ microcentrifuge tubes on ice until plasma was isolated by centrifugation. Samples were then frozen at $-20^{\circ} \mathrm{C}$ before RIA for cortisol. To minimize possible effects of circadian variations in glucocorticoid concentrations, blood samples were collected between 12:30 and 4:30 P.M. For fish in community settings, blood constituents in the final sample were determined by a standard hematological analysis (Department of Laboratory Animal Medicine, Stanford University).

Cortisol levels were determined using a competitive binding RIA kit (MAGIC cortisol; Ciba Corning, Medfield, MA) with the following alterations to the protocol: standards were diluted 10-fold in PBS, antibody was diluted twofold in PBS, and samples were incubated for $3.5 \mathrm{hr}$ at room temperature.

\section{Necropsy and immunostaining}

After the final blood sample was taken, fish were killed by rapid cervical transection, and their standard length and weight were measured. The brains were removed and immersion-fixed in $4 \%$ paraformaldehyde in 0.2

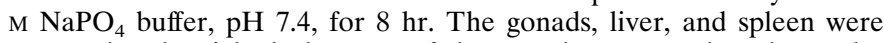
removed and weighed, the state of the gonads was noted, and gonadosomatic, hepatosomatic, and splenosomatic indices were calculated: organosomatic index $=[$ organ weight $(\mathrm{gm}) /$ body weight $(\mathrm{gm})] \times 100$.

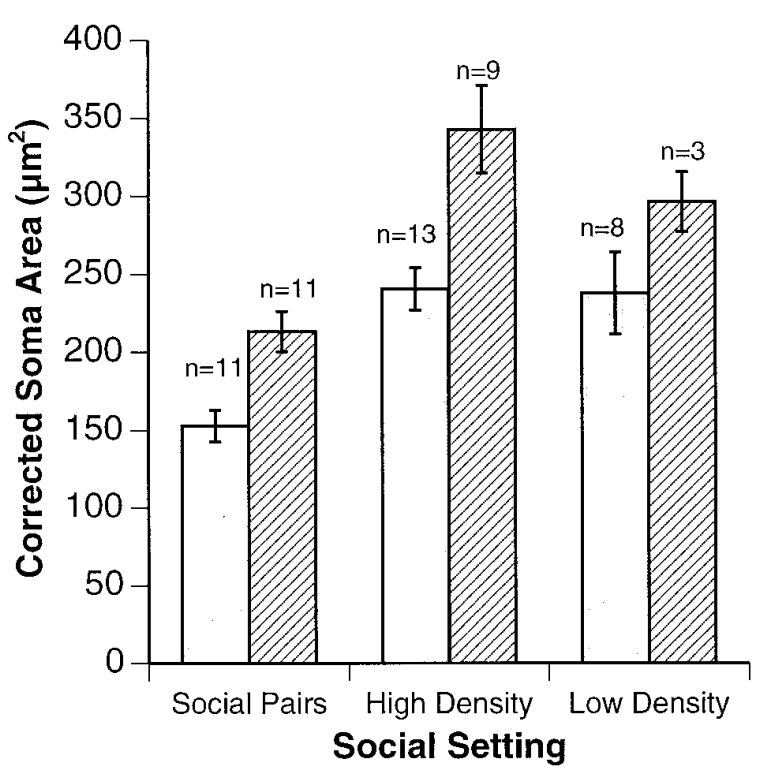

Figure 3. irGnRH soma sizes, corrected for body size, are shown for T and NT males in all three social settings studied. In all experimental groups, soma sizes are significantly smaller for NTs (open bars) than for Ts (striped bars) $(p<0.002$ for social pairs; $p<0.01$ for community settings; Student's $t$ test). Error bars represent SEM.

Fixed brains were cryoprotected overnight at $4^{\circ} \mathrm{C}$ in $30 \%$ sucrose, frozen at $-20^{\circ} \mathrm{C}$, and then sagittally sectioned at $40 \mu \mathrm{m}$ (Microm). Immunoreactive $\mathrm{GnRH}$ cells (irGnRH) were labeled with antibodies to synthetic $\left[\mathrm{Arg}^{8}\right] \mathrm{GnRH}$ (no. 20075, Incstar, Stillwater, MN) and visualized with 3,3-diaminobenzidine (Sigma, St. Louis, MO) (Davis and Fernald, 1990).

\section{Cell size measurements}

Cross-sectional area of the GnRH-containing neurons directly reflects the reproductive competence of male H. burtoni (Davis and Fernald, 1990). For this reason, we used soma size as a measure of the effects of social manipulations. Soma sizes of irGnRH neurons in the POA were measured using images from a microscope (Zeiss axiophot, $600 \times$ total magnification) that were captured for computer analysis (National Institutes of Health Image, 1.51, Wayne Rasband). The crosssectional area of the soma was measured only if the nucleus and borders of the cell could be clearly discerned. The number of labeled cells measured per subject was 50, approximately one-fourth of the total preoptic GnRH neuron pool (Davis and Fernald, 1990). Each of five additional fish had between 24 and 44 labeled cells; these were also included for analysis because the SEMs were within the range of those fish with 50 cells measured. One fish was excluded from pooled analyses because it had changed status 4 weeks before it was killed and was not considered to be in a stable state (Nguyen, 1996). There was a significant relationship between GnRH soma size and social status, but because soma size can be correlated with body size, we corrected the soma size measurements for body weight, following the procedure described in White and Fernald (1993).

\section{Quantitative evaluations}

Statistical analysis was conducted using JMP IN software (SAS Institute). Nonparametric tests were used when the data were not normally distributed. In all cases, the minimum significance level was set at $p<0.05$.

\section{RESULTS}

\section{Social pairs}

\section{GnRH neuronal soma size and gonadosomatic index (GSI)}

Isolation of pairs of males in a dominance relationship produced a highly significant difference in the average size of preoptic irGnRH neuronal populations between Ts and NTs (Fig. 3) $(p<0.002 ; n=11$ pairs). There were similarly 

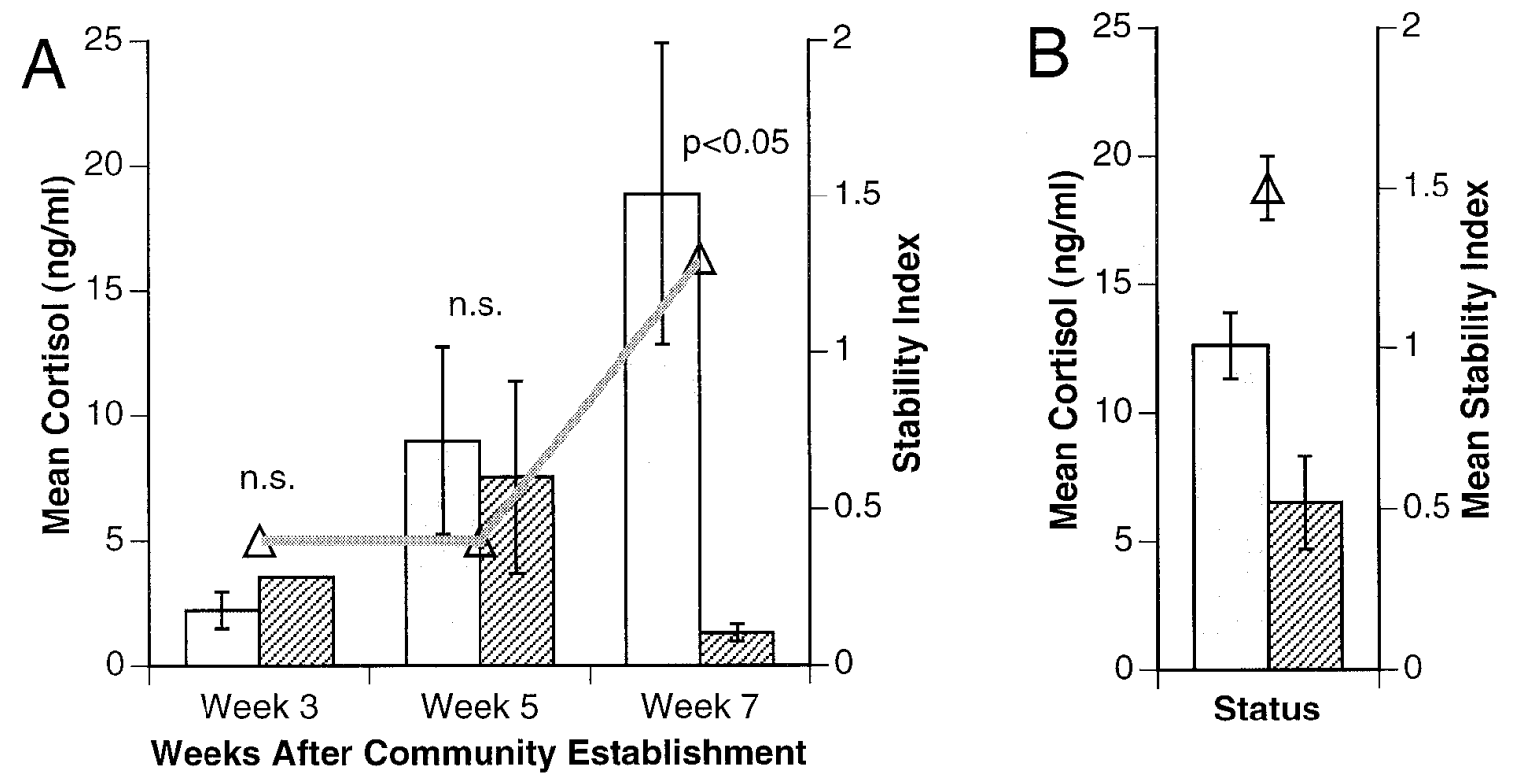

Figure 4. Cortisol levels of NTs (open bars) and Ts (striped bars) shown for $(A)$ low-density communities and $(B)$ high-density communities (averaged). In both cases, the stability index $(\Delta)$ (see Materials and Methods) is superimposed on cortisol level data. In the low-density setting, differences in cortisol levels are plotted over the course of 7 weeks. High-density communities had been established for 2 months before blood sampling and are fully stabilized.

profound differences in gonad size between Ts and NTs, with Ts having significantly larger testes $(\mathrm{T}=0.50 \pm 0.21 \mathrm{SE} ; \mathrm{NT}=$ $0.19 \pm 0.14 \mathrm{SE} ; p<0.001)$.

\section{Stress profiles}

Across social pairs, NTs experienced more stress than Ts, as indicated by a marginal trend toward higher $(\mathrm{NT}=4.0 \mathrm{ng} / \mathrm{ml}$; $\mathrm{T}=2.3 \mathrm{ng} / \mathrm{ml} ; p=0.076 ; n=28$ pairs $)$ and more variable $(p<$ $0.05 ; F$ test) cortisol levels. This trend became significant under certain social and maturational conditions. Notably, in older fish that had been in stable pairs for 2 weeks, Ts had lower cortisol levels than NTs $(\mathrm{T}=1.1 \mathrm{ng} / \mathrm{ml} \pm 0.9 \mathrm{SE} ; \mathrm{NT}=3.7 \mathrm{ng} / \mathrm{ml} \pm 0.9$ $\mathrm{SE} ; p<0.05)$. Among younger fish, or during the first week of pairing of older fish, cortisol levels were not significantly different between NTs and Ts.

\section{Community settings}

\section{GnRH neuronal soma size and GSI}

As in social pairs, Ts from both high- and low-density community settings had larger GnRH-containing neurons within their POAs than NTs (Fig. 3) ( $p<0.01$; Student's $t$ test). Soma size was also negatively correlated with cortisol levels in blood sampled within the previous week ( $p<0.05$; Spearman Rho) but not in blood sampled 3 or more weeks previously. Furthermore, there was a significant negative correlation between soma size and nonterritorial behavior ( $p<0.05$; Spearman Rho). Recent work revealed that 3 weeks are needed for neurons to shrink within individual fish that are descending in social status and only 1 week for neurons to enlarge when fish are ascending (Nguyen, 1996). In the current study, a T male in the low-density tank that switched to NT status 4 weeks before necropsy retained a large average soma size $\left(339 \mu \mathrm{m}^{2}\right)$ despite recent stressful experiences, as indicated by its high cortisol levels $(>45.0 \mathrm{ng} / \mathrm{ml})$. Likewise, an NT male that became $\mathrm{T}$ at a similar time had large $\mathrm{GnRH}$ neurons at necropsy, supporting the observation that the biological change is biased toward the dominant state. This fish had relatively low cortisol levels throughout the study $(1.9,5.9$, and $4.6 \mathrm{ng} / \mathrm{ml})$. Ts had a significantly higher mean GSI $(\mathrm{T}=0.57 \pm 0.04 \mathrm{SE} ; \mathrm{NT}=$ $0.43 \pm 0.03 \mathrm{SE} ; p<0.01$; Student's $t$ test), confirming their greater reproductive potential. Ts weighed more than NTs $(\mathrm{T}=$ $17.7 \mathrm{gm} \pm 0.7 \mathrm{SE} ; \mathrm{NT}=15.6 \mathrm{gm} \pm 0.5 \mathrm{SE} ; p<0.01$; Student's $t$ test) but were not significantly longer.

\section{Stress profiles}

NTs had significantly higher cortisol levels than Ts in the pooled high-density tanks, indicating that they experienced more stress (Fig. 4) ( $p<0.05$; Wilcoxon signed rank). Furthermore, the range of cortisol levels was significantly wider for NTs than Ts (0.7-45.0 vs $0.6-11.5 \mathrm{ng} / \mathrm{ml} ; p<0.05 ; F$ test).

In contrast to the high-density tanks, which had been established 2 months before the first sampling date, the low-density tank was established only 3 weeks before the first sampling date. Blood samples therefore reflected the development over time of the difference in cortisol levels as this tank community stabilized. There was not a significant difference between Ts and NTs on the first two sample dates, 3 and 5 weeks after tank establishment. By the final sample date, 7 weeks after tank establishment, the Ts had significantly lower cortisol levels than NTs (Fig. 4). Accompanying the emerging difference in cortisol was an increase in the stability index, suggesting that the dominance hierarchy had developed and stabilized ( $p<0.05$; Wilcoxon rank sum). This index increased from 0.4 for each of the first two sample dates to 1.3 for the third. As a point of comparison, the mean stability index for the high-density tanks was $1.5 \pm 0.1 \mathrm{SE}$, confirming that these tanks had stabilized earlier. This index numerically reflects the observed changes in the low-density tank dynamics: by the first blood sampling there were two Ts, four NT/T transition males, and eight NTs. The two Ts were not able to defend their territories, and by the next sampling date, two new Ts had recently established dominance. These two fish were able to maintain their territories and remained the sole Ts; there was only 1 other NT/T and 11 NTs. 


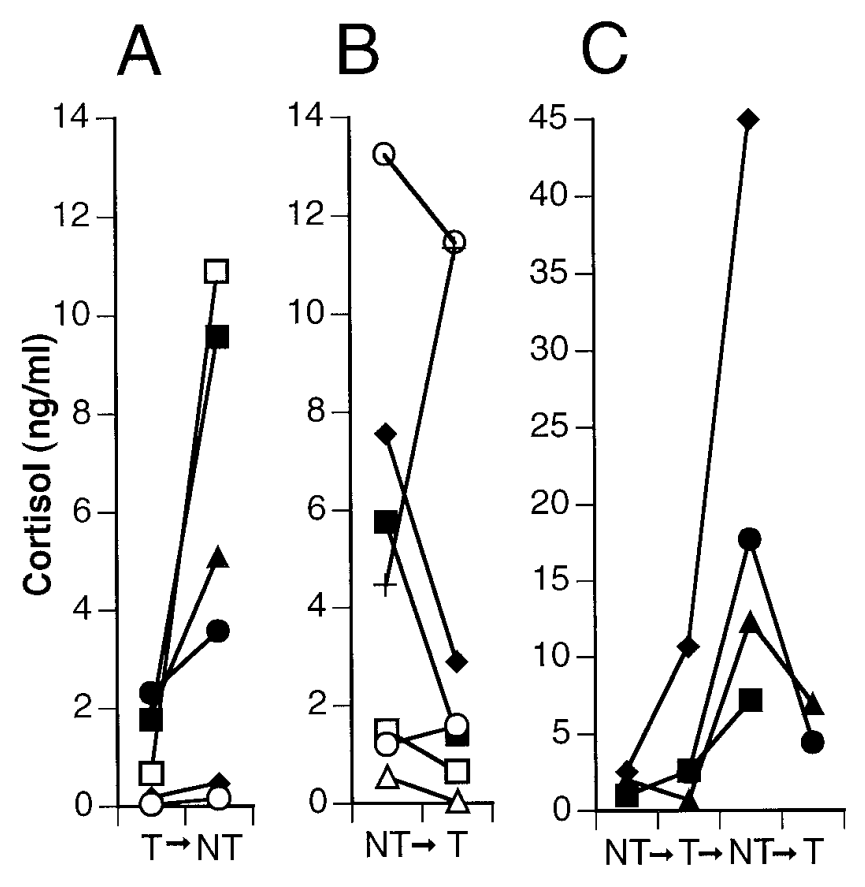

Switches in Status

Figure 5. Cortisol levels in individual fish that switched social status. $A$, Single switches from T to NT; $B$, single switches from NT to T; $C$, multiple switches (note different ordinate scale in $C$ ). Fish had significantly higher cortisol levels as NT than as $\mathrm{T}(p<0.05$; Wilcoxon signed rank, using last switch if multiple switches per fish).

\section{Cortisol levels after a spontaneous switch in social status}

During the course of these experiments, some fish spontaneously switched their social state. Despite attempts to maintain fish in stable dominance relationships in the social pairs study, four pairs switched social status relative to one another. In community tanks, a total of 14 switches in nine fish occurred, with some fish switching back and forth. Pooled experiments indicated that 17 fish switched a total of 22 times, 12 times from NT to T and 10 times from T to NT (Fig. 5). In all but four of these cases, cortisol levels were lower when a fish was T than when it was NT. On the basis of both social pair and community setting switches, a fish had significantly higher levels of cortisol as an NT than as a T $(p<0.01$; Wilcoxon signed rank). In six cases in which Ts relinquished dominance and became NTs (Fig. 5), their cortisol levels before the switch were similar to those of stable Ts (range for Ts that switched: $0.05-2.3 \mathrm{ng} / \mathrm{ml}$ vs $0.5-13.0 \mathrm{ng} / \mathrm{ml}$ for stable Ts), suggesting that something other than cortisol was responsible for their loss of dominance. In contrast, however, two NTs that showed heightened cortisol levels after they became territorial were incapable of maintaining territories. After reverting to the NT state, one of these fish had the highest serum cortisol levels observed in this study ( $45 \mathrm{ng} / \mathrm{ml})$. This observation suggests the opposite scenario in which Ts exhibiting large cortisol responses to aggressive interactions are unable to maintain their dominance.

\section{Overall health indices}

There were no significant differences between the overall health of Ts and NTs as measured by organosomatic indicators of health and condition (hepatosomatic index, splenosomatic index)
(Goede and Barton, 1990) or by standard hematological components (white blood cell count, red blood count, hemoglobin, hematocrit). This indicates that the differences in cortisol levels between $\mathrm{T}$ and NTs are not associated with differences in the physical health of the fish.

\section{DISCUSSION}

These results show that in $H$. burtoni stress depends not only on the social state of the individual but also on the stability of the social community in which the animal lives. In addition, our data extend previous reports on the relationship between social and reproductive states in male $H$. burtoni into more complex social arenas, because in all social settings Ts had larger irGnRHcontaining neurons and GSIs than NTs (for review, see White and Fernald, 1997). Taken together, these results suggest that cortisol may serve as an endogenous signal relating the social environment to an animal's social status and/or internal reproductive state.

The distinct stress profiles of male fish in different social contexts indicate that cortisol levels responded to social dynamics. In all stable settings, Ts had lower serum cortisol than NTs (Fig. 4), but the emergence of this difference varied depending on the experimental group and the degree of social stability. Among social pairs, the cortisol difference was significant only during the second week of pairing among older fish, suggesting that stress levels decreased in Ts and increased in NTs as social relationships became established. This idea is borne out in community settings, where the development of social stability was explicitly examined. In high-density tanks, fish acclimated for 2 months before the start of the experiment. As a result, societies were already stable when initial observations were made, as seen in the high stability index (1.54; Fig. 4). In these tanks, Ts and NTs had significantly different levels of cortisol overall. In contrast, observations of the low-density tank began early enough to document the establishment of the social hierarchy. Switches in social state were initially frequent as males struggled for dominance. When emergent Ts succeeded in maintaining their territories over several weeks, the stability index increased from below 0.5 to 1.33 , close to the stabilized, high-density tanks. At the same time, significant differences between T and NT cortisol levels became apparent. Thus, early in the process of establishing a social hierarchy, both social relationships and rank-related stress levels stabilized.

In addition to corresponding to the social stability of a community, cortisol levels also reflected the social state of individual fish. This is highlighted in the 22 cases in which blood samples were taken before and after each spontaneous switch in social status (Fig. 5). In general, cortisol concentration is a noisy variable, varying widely among fish, so it is instructive to compare levels associated with the T and NT state in the same individual as it undergoes a social transition. In 18 of these cases, cortisol levels were lower within a male fish when it was $\mathrm{T}$ than when it was NT.

It is not intuitively obvious why the $\mathrm{T}$ state should be associated with less stress than the NT state. There are at least as many examples of species in which dominant animals have higher basal glucocorticoid levels than subordinates as the reverse (for review, see Sapolsky, 1982; Creel et al., 1996). In H. burtoni, Ts alternate between agonistic interactions with neighboring Ts and active solicitations of females while remaining vigilant against femalemimicking NTs. During the first month of community establishment, individuals behaved either as predominantly aggressive Ts or as subordinate NTs; yet both types of activities produced similar levels of cortisol (Fig. 4). Thus, early in community estab- 
lishment the two social states are equally stressful. Over time, as the stability index decreased, cortisol levels in Ts decreased and those in NTs increased (Fig. 4). Although glucocorticosteroid levels can vary as a function of activity (Hahn et al., 1995), a T male's "chase" is roughly equivalent in distance and duration to an NT male's "flee," suggesting that factors other than activity level are responsible for the emerging cortisol differences. Moreover, we have measured basal cortisol levels in $H$. burtoni (P. Hyde and R. Fernald, unpublished observations) which confirm that the activity alone cannot account for our data. Once a T male was stably situated, its territorial displays became ritualized. Conversely, the stressful experiences of NTs heightened, as exclusion from food or harassment from an established $\mathrm{T}$ male had a more severe effect than when these same events had occurred amid social flux.

Another interpretation of these data is that NTs had higher serum cortisol concentrations attributable to crowding stress (Vijayan and Leatherland, 1990) or poor health (for review, see Johnson et al., 1992) rather than social stress caused by low position in the dominance hierarchy. There were no significant differences, however, between NTs and Ts for any of the methods we used to asses their physical health; nor do NTs exhibit higher stress levels simply because of crowding in tanks, because average cortisol levels for NTs overlapped between high- and low-density settings (Fig. 4). Instead, cortisol levels seem to differ according to social experience.

Because cortisol levels both track the dynamics of the overall social scene and correlate with individual social status, it is possible that integration of the cortisol signal could serve as an endogenous determinant of behavioral and/or reproductive state. If stress physiology predicts social status (Johnson et al., 1996), individuals with lowered cortisol responses should preferentially become dominant. Alternatively, if stress levels result from social status, once any individual fish becomes $\mathrm{T}$, it may lead a less stressful life. Current observations are equivocal with either interpretation (see Results). Experiments are currently under way to test explicitly for a causal role of cortisol in social statedetermination, using implants of both cortisol and a cortisol antagonist (S. White, I. Yun, M. Benson, unpublished observations).

The size of GnRH-containing neurons in the POA of male $H$. burtoni also reflects social experience: Ts have significantly larger average neurons than NTs in each of the experimental setups tested (Fig. 3). As with cortisol levels, the difference in GnRH neuronal magnitude seems to correspond to both individual social state and overall social environment. Differences were most extreme in the social pair setup, followed by high-density tanks with stable social structure. The low-density tank showed the smallest, although still significant, difference. Interestingly, soma sizes for both Ts and NTs in community tanks tended to be larger than in the social pairs, raising the possibility that GnRH production scales with social setting. This is currently being investigated. Because cortisol and GnRH cell size each reflect individual and overall social states, it is tempting to speculate that integration of the cortisol signal could lead to changes in $\mathrm{GnRH}$ neuronal size. In the hypothalamus, cortisol might produce effects on GnRH neurons directly (Ahima and Harlan, 1992; Chandran et al., 1994); alternatively, the hypothalamic stress factor corticotropin-releasing hormone could influence GnRH cell size (Rivier and Vale, 1984; MacLusky et al., 1988). It should be noted that in birds (Hahn et al., 1995) and reptiles (Denardo and Licht, 1993 ) it has been proposed that glucocorticosteroids can influence reproductive behavior without inhibiting reproductive hormones. In $H$. burtoni, however, the soma size and behavior are both different between Ts and NTs, which is not consistent with independent action of cortisol directly on behavior.

In this study, data from the social pair setting do not support a role for cortisol in causing GnRH neuronal plasticity. Here, GnRH neuronal soma size differences are highly significant between Ts and NTs, yet differences in cortisol were the least robust. It is possible that the extreme differences in $\mathrm{GnRH}$ neuron size were attributable to experimental preselection for socially stable animals (see Materials and Methods). In other studies in which fish were paired (Pottinger, 1992; Balm et al., 1994), dominance relationships formed quickly and were associated with significant cortisol elevations in the subordinate animal relative to the dominant one within $3 \mathrm{hr}$ (Balm et al., 1994). The insignificant cortisol difference across all social pairs in our study could reflect the novelty ( 2 weeks) of the social relationship, as during community formation in the low density tank, or alternatively, a suppression of the stress axis in subordinate animals (Blanchard et al., 1993). Whatever the reason for the insignificant cortisol difference, stress profiles and GnRH neuronal soma sizes seem to be uncoupled in this setting.

In community tanks, cortisol levels of individual fish do seem to provide a fluid tracking of the ongoing social scene, with changes in GnRH neuronal soma size taking longer to become manifest (see Results). Integration of cortisol levels may endogenously mediate between social setting and social state, between social setting and reproductive state, or both. Alternatively, cortisol may simply be a correlate of these. Future studies using implants to either block or augment cortisol levels should resolve these possibilities. Furthermore, examination of cortisol levels in females that exhibit reproductively regulated cyclical changes in $\mathrm{GnRH}$ neuronal soma size but do not exhibit differences in social rank (White and Fernald, 1993) could also distinguish effects restricted to reproductive, rather than social, states.

\section{REFERENCES}

Ahima RS, Harlan RE (1992) Glucocorticoid receptors in LHRH neurons. Neuroendocrinology 56:845-850.

Alberts SC, Altmann J, Sapolsky RM (1992) Behavioral, endocrine, and immunological correlates of immigration by an aggressive male into a natural primate group. Horm Behav 26:163-173.

Balm PHM, Pepels P, Helfrich S, Hovens MLM, Wendelaar Bonga SE (1994) Adrenocorticotropic hormone in relation to interrenal function during stress in tilapia (Oreochromis mossambicus). Gen Comp Endocrinol 96:347-360.

Bass A (1992) Dimorphic male brains and alternative reproductive tactics in a vocalizing fish. Trends Neuroci 15:139-145.

Bennett NC, Faulkes CG, Molteno AJ (1996) Reproductive suppression in subordinate, non-breeding female Damaraland mole-rats: two components to a lifetime of socially induced infertility. Proc R Soc Lond [Biol] 263:1599-1603.

Billiard R, Bry C, Gillet T (1981) Stress, environment, and reproduction in teleost fish. In: Stress and fish (Pickering AD, ed), pp 185-208. London: Academic.

Blanchard DC, Sakai RR, McEwen B, Weiss SM, Blanchard RJ (1993) Subordination stress: behavioral, brain, and neuroendocrine correlates. Behav Brain Res 58:113-121.

Cardwell JR, Liley NR (1991) Androgen control of social status in males of a wild population of stoplight parrotfish, Sparisome viride (Scaridae). Horm Behav 25:1-18.

Cardwell JR, Sorensen PW, Van Der Kraak GJ, Liley NR (1996) Effect of dominance status on sex hormone levels in laboratory and wildspawning male trout. Gen Comp Endocrinol 101:333-341.

Chandran U, Attardi B, Friedman R, Dong KW, Roberts JL, DeFranco DB (1994) Glucocorticoid receptor-mediated repression of gonad- 
otropin-releasing hormone promoter activity in GT1 hypothalamic cell lines. Endocrinology 134:1467-1474.

Creel S, Creel NM, Monfort SL (1996) Social stress and dominance. Nature 379:212.

Davis MR, Fernald RD (1990) Social control of neuronal soma size. J Neurobiol 21:1180-1188.

Denardo DF, Licht P (1993) Effects of corticosterone on social behavior of male lizards. Horm Behav 27:184-199.

Faulkes CG, Abbott DH, Jarvis JUM (1991) Social suppression of reproduction in male naked mole-rats, Heterocephalus glaber. J Reprod Fertil 91:593-604.

Fernald RD (1977) Quantitative behavioral observations of Haplochromis burtoni under semi-natural conditions. Anim Behav 25:643-653.

Fernald RD, Hirata N (1977a) Field study of Haplochromis burtoni: habitats and co-habitants. Environ Biol Fishes 2:299-308.

Fernald RD, Hirata N (1977b) Field study of Haplochromis burtoni: quantitative behavioral observations. Anim Behav 25:964-975.

Fernald RD, Hirata N (1979) The ontogeny of social behavior and body coloration in the African cichlid fish Haplochromis burtoni. Z Tierpsychol 50:180-187.

Fraley NB, Fernald RD (1982) Social control of developmental rate in the African cichlid, Haplochromis burtoni. Z Tierpsychol 60:66-82.

Francis RC, Soma KK, Fernald RD (1993) Social regulation of the brain-pituitary-gonadal axis. Proc Natl Acad Sci USA 90:7794-7798.

Goede RW, Barton BA (1990) Organismic indices and an autopsy-based assessment as indicators of health and condition of fish. In: Biological indicators of stress in fish (Adams SM, ed), pp 93-108. Bethesda, MD: American Fisheries Society.

Gust DA, Gordon TP, Hambright MK, Wilson ME (1993) Relationship between social factors and pituitary-adrenocortical activity in female rhesus monkeys (Macaca mulatta). Horm Behav 27:318-331.

Hahn TP, Wingfield JC, Mullen R, Deviche PJ (1995) Endocrine bases of spatial and temporal opportunism in Arctic-breeding birds. Am Zool 35:259-273

Kao MHF (1993) Social status and stress hormones in Haplochromis burtoni. PhD thesis, Stanford University.

Johnson EO, Kamilaris TC, Chrousos GP, Gold PW (1992) Mechanisms of stress: a dynamic overview of hormonal and behavioral homeostasis. Neurosci Biobehav Rev 16:115-130.

Johnson EO, Kamilaris TC, Carter CS, Calogero AE, Gold PW, Chrousos GP (1996) The behavioral consequences of psychogenic stress in a small, social primate (Callithrix jacchus jaccus). Biol Psychol 40:317-337.

Leitz T (1987) Social control of testicular steroidogenic capacities in the Siamese fighting fish Betta splendens Regan. J Exp Zool 244:473-478.

McKittrick CR, Blanchard DC, Blanchard RJ, McEwen RJ, Sakai RR (1995) Serotonin receptor binding in a colony model of chronic social stress. Biol Psychol 37:383-393.

MacLusky NJ, Naftolin F, Leranth C (1988) Immunocytochemical evidence for direct synaptic connections between corticotropin-releasing factor (CRF) and gonadotropin-releasing hormone (GnRH)containing neurons in the preoptic area of the rat. Brain Res 439:391-395.

Manogue K, Candland D, Leshner A (1975) Dominance status and adrenocortical reactivity to stress in squirrel monkeys (Saimiri scuireus). Primates 16:457-463.

Meisfeld R, Rusconi S, Godowski PJ, Maler BA, Okret S, Wikstrom A-C, Fustafsson J-A, Yamomoto KR (1986) Genetic complementation of a glucocorticoid receptor deficiency by expression of cloned receptor cDNA. Cell 46:369-399.

Moore FL, Miller LJ (1984) Stress-induced inhibition of sexual behavior: corticosterone inhibits courtship behaviors of a male amphibian (Taricha graulosa). Horm Behav 18:400-410.

Nguyen T (1996) Asymmetry in the social regulation of preoptic area irGnRH neuronal soma size in Haplochromis burtoni. PhD thesis, Stanford University.

Pankhurst NW, Barnett CW (1993) Relationship of population density, territorial interaction and plasma levels of gonadal steroids in spawning male demoiselles Chromis dispulis (Pisces: Pomacentridae). Gen Comp Endocrinol 90:168-176.

Payman BC, Swanson HH (1980) Social influence on sexual maturation and breeding in the female mongolian gerbil (Meriones unguiculatus). Anim Behav 28:528-535.

Pickering AD, Pottinger TG, Carragher J, Sumpter JP (1987) The effects of acute and chronic stress on the levels of reproductive hormones in the plasma of mature male brown trout. Gen Comp Endocrinol 68:249-259.

Pottinger TG (1992) The influence of social interaction on the acclimation of rainbow trout, Oncorhynchus mykiss (Walbaum) to chronic stress. J Fish Biol 41:435-447.

Rivier C, Rivest S (1991) Effect of stress on the activity of the hypothalamic-pituitary-gonadal axis: peripheral and central mechanisms. Biol Reprod 45:523-532.

Rivier C, Vale W (1984) Influence of corticotropin-releasing factor on reproductive functions in the rat. Endocrinology 114:914-921.

Saltzman W, Schultz-Darken NJ, Abbott DH (1996) Behavioral and endocrine predictors of dominance and tolerance in female common marmosets, Callithrix jacchus. Anim Behav 51:657-674.

Sapolsky RM (1982) The endocrine stress-response and social status in the wild baboon. Horm Behav 16:279-292.

Sapolsky RM (1986) Endocrine and behavioral correlates of drought in wild olive baboons (Papio anubis) Am J Primatol 11:217-227.

Sapolsky RM (1993) Endocrinology alfresco: psychoendocrine studies of wild baboons. In: Recent progress in hormone research, Vol 48 (Bardin CW, ed), pp 437-468. San Diego: Acadamic.

Schreck C (1981) Stress and compensation in teleostan fishes: responses to social and physical factors. In: Stress and fish (Pickering AD, ed), pp 295-321. London: Academic.

Schwabl H, Ramenofsky M, Schwabl-Benzinger I, Farner DS, Wingfield JC (1988) Social status, circulating levels of hormones, and competition for food in winter flocks of the white-throated sparrow. Behavior 107:107-121.

Vijayan MM, Leatherland JF (1990) High stocking density affects cortisol secretion and tissue distribution in brook charr, Salvelinus fontainalis. J Endocrinol 124:311-318.

Wendelaar Bonga SE, Balm PHM, Lamers AE (1995) The involvement of ACTH and MSH in the stress response in teleost fish. Neth J Zool 45:103-106.

White SA, Fernald RD (1993) Gonadotropin-releasing hormonecontaining neurons change size in female Haplochromis burtoni. J Neurosci 13:434-441.

White SA, Fernald RD (1997) Changing through doing: behavioral influences on the brain. In: Recent progress in hormone research, Vol 52 (Conn PM, ed), pp 455-474. Bethesda, MD: The Endocrine Society. 